\title{
Crise ambiental e sociedade de risco: o paradigma das alterações climáticas diante do direito ambiental e da sustentabilidade
}

\author{
${\text { Danilo Barbosa de } \text { Arruda }^{1} \text { (D), Belinda Pereira da Cunha }}^{2,3}$ (D) \& Geraldo Milioli ${ }^{1,4}$ (D)
}

(1) Universidade do Extremo Sul Catarinense, Programa de Pós-Graduação em Ciências Ambientais, Avenida Universitária 1105, Universitário 88806-000, Criciúma, Santa Catarina, Brasil. E-mail: danilobarruda@gmail.com

(2) Universidade Federal da Paraíba - campus I, Centro de Ciências Jurídicas, Jardim Universitário, Castelo Branco 58051-900, João Pessoa, Paraíba, Brasil. E-mail: belindacunha@hotmail.com

(3) Universidade Federal da Paraíba - campus I, Centro de Ciências Jurídicas, Programa de Pós-Graduação em Ciências Jurídicas, Jardim Universitário, Castelo Branco 58051-900, João Pessoa, Paraíba, Brasil.

(4) Universidade do Extremo Sul Catarinense, Avenida Universitária 1105, Universitário 88806-000, Criciuma, Santa Catarina, Brasil. E-mail: gmi@unesc.net

Arruda D.B., Cunha B.P. \& Milioli G. (2020) Crise ambiental e sociedade de risco: o paradigma das alterações climáticas diante do direito ambiental e da sustentabilidade. Pesquisa e Ensino em Ciências Exatas e da Natureza, 4: e1461. http://dx.doi.org/10.29215/pecen.v4i0.1461

Editor acadêmico: Hugo da Silva Florentino. Recebido: 31 janeiro 2020. Aceito: 17 julho 2020. Publicado: 24 julho 2020.

Resumo: A urgência da crise ambiental e suas implicações ensejam a humanidade a repensar a sociedade de risco. Os objetivos deste manuscrito visam compreender e questionar o paradigma das alterações climáticas no semiárido nordestino. A metodologia utilizada é a bibliográfica e dedutiva, pois faz uma incursão teórica em autores internacionais e nacionais que corroboram com a análise conceitual do artigo. As conquistas sociais e os direitos já garantidos estão em constante ameaça com a transformação rápida advinda das extenuantes e inesperadas mudanças socioclimáticas. Os principais resultados encontrados foram a constatação do prejuízo socioambiental e os impactos das alterações climáticas resultantes das atividades humanas, assim como a insustentabilidade do uso intensivo dos recursos naturais da Caatinga.

Palavras chave: Mudanças climáticas, crise civilizatória, insustentabilidade, racionalidade ambiental, reflexão ambiental.

Environmental crisis and risk society: the paradigm of climate change in the face of environmental law and sustainability

Abstract: The urgency of the environmental crisis and its implications enable humanity to rethink the risk society. The goals of this manuscript are to understand and question the paradigm of climate change in northeastern semiarid. The methodology used is bibliographic and deductive, as it makes a theoretical foray into international and national authors who corroborate with the conceptual analysis of the article. Social achievements and rights already guaranteed are in constant threat with the rapid transformation resulting from strenuous and unexpected socio-climatic changes. The main results found were the verification of socio-environmental damage and the impacts of climate change resulting from human activities as well as the unsustainability of the intensive use of Caatinga natural resources.

Key words: Climate change, civilization crisis, unsustainability, environmental rationality, environmental reflection. 


\section{Introdução}

O presente artigo tem a intenção de trazer para o debate os paradoxos da sociedade ocidental, seu modus operandi e as incoerências que impossibilitam a existência de vida. Neste panorama, os paradigmas da sociedade de risco, com seu modelo econômico vigente e as relações de produção e poder geram contradições que inviabilizam as dinâmicas naturais e os ciclos ecológicos. Neste sentido, para tentar fazer um contraponto e compreender as implicações de ordem jurídico-ambiental diante das mudanças climáticas se justifica a escrita deste artigo.

O mesmo está dividido em três seções. A primeira trata da Sociedade de risco, da crise ambiental e dos reflexos no direito e na sustentabilidade. Na segunda seção abordam-se as mudanças climáticas no semiárido nordestino e, por fim, a terceira e última seção trabalha-se o interesse público e função do Estado no controle e gerenciamento da desertificação.

A metodologia empregada é a bibliográfica e dedutiva, a partir da análise dos dados secundários encontrados em sites, livros e periódicos que abordam de modo interdisciplinar essa problemática complexa. A insustentabilidade do modo de produção, a situação de consumo e da própria composição da sociedade de massas pautada pelo acúmulo, imediatismo, utilitarismo e concentração de riquezas implica em riscos, alguns incontroláveis e insolúveis, para a humanidade que ensejam uma visão integrada por parte do direito ambiental e da sustentabilidade que intentam obstar o colapso climático.

\section{Sociedade de risco, crise ambiental e reflexos no direito e na sustentabilidade}

O processo de civilizatório e a construção global dos ditames histórico-sociais demonstram que a lógica do mercado é atribuir preço a tudo que possa ser valorizado ou etiquetado. Assim sendo, haverá uma continuidade da expansão de mercadorias o que, por sua vez, possibilita a corrente globalização mundial. Entretanto, a lógica da rápida e invasiva expansão comercial e econômica não considera os efeitos a longo prazo que afetam os seres humanos e a vida selvagem. De modo que, não se pode perpetuar a lógica do mercado em detrimento do meio ambiente, ameaçando a igualdade social e os direitos já conquistados historicamente. Com o pretexto de que, ilusoriamente, o ter significa qualidade de vida e status social, o crescimento econômico desenfreado consegue liberalização para prosseguir com sua ortodoxia comumente competitiva, desigual e injusta. Assim, muitas ambiguidades estão exalando suas falhas, pois as brechas do sistema mostram as facetas cruéis e degradantes que estão por trás da falsa impressão de bem viver.

Nessa toada, a sociedade de riscos assume riscos que são incontroláveis, compromissos imediatistas dos quais não se têm controle e, muito menos, limitação e alternativa para lidar com seus paradoxos. Engendrando perigos que, atualmente, ainda não se tem respostas à sua altura. Não obstante, o excerto adiante corrobora com este entendimento e acrescenta que a globalização acentuou os múltiplos riscos da sociedade:

\footnotetext{
Contido na globalização, e ainda assim claramente distinto dela, há um padrão de distribuição dos riscos no qual se encontra um material politicamente explosivo: cedo ou tarde, eles alcançam inclusive aqueles que os produziram ou que lucraram com eles. Em sua disseminação, os riscos apresentam socialmente um efeito bumerangue: nem os ricos e poderosos estão seguros diante deles. Os anteriormente "latentes efeitos colaterais" rebatem também sobre os centros de sua produção. Os atores da modernização acabam, inevitável e bastante concretamente, entrando na ciranda dos perigos que eles próprios desencadeiam e com os quais lucram. Isto pode ocorrer de diversas formas (Beck 2010: 44).
}

Nessa conjectura, o ordenamento jurídico se adequou às novas lutas sociais e procura difundir que a fundamentalidade do direito ao ambiente natural expressa-se na garantia de sua qualidade como condição imprescindível ao desenvolvimento das potencialidades individuais lato senso. Sendo um direito prima facie, como todo direito fundamental, o ambiente natural atinge seus contornos definitivos na relação de reciprocidade entre sociedade e natureza. Ao 
mesmo tempo, enquanto o direito fundamental ao ambiente natural e seus recursos assume sua dimensão sociocultural, via de regra os demais direitos fundamentais assumem sua condição ambiental e de sistema valorativo (Silva 2008).

Como direito fundamental, o meio ambiente é considerado essencial ao pleno desenvolvimento humano, as condições ambientais e sociais que dão suporte à vida têm o precípuo interesse sociocultural. Não obstante, a padronização dos costumes e exponencial crescimento econômico implica maiores impactos ao meio ambiente, chamando a atenção para o deslocamento geográfico das fontes de recursos, do Sul para o Norte, e das áreas de descarte dos resíduos, dos países ricos (Norte) para os pobres $(\mathrm{Sul})^{1}$. É a velha relação de escambo dos tempos coloniais, agora com outra conotação, demonstrando a dependência de recursos naturais e matérias-primas para atender a alta demanda dos países industrializados (Alier 2007).

O que está acontecendo é uma inversão da destruição e armazenagem dos resíduos e recursos, dos países ricos para os pobres. Sem enumerar o vil

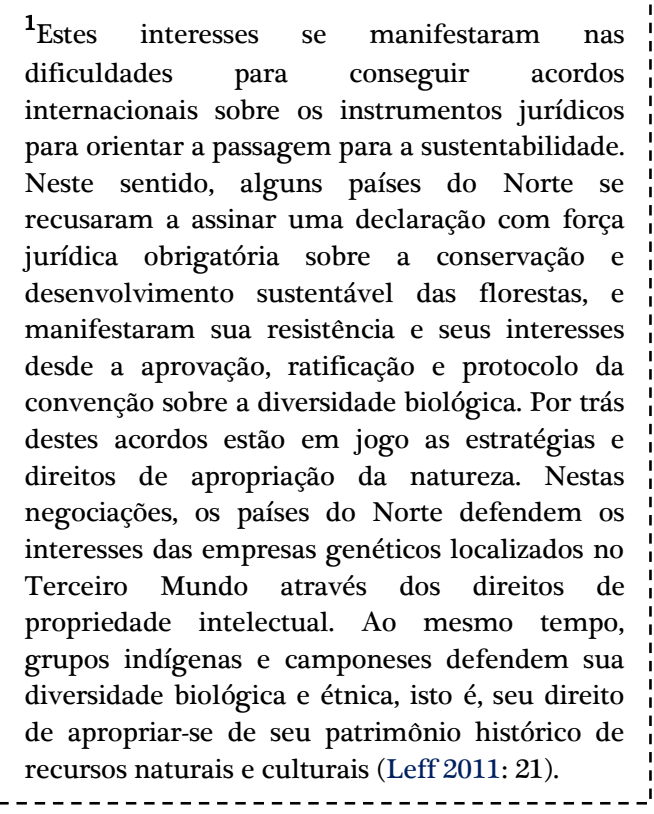
preço da exploração e rastro destrutivo nos campos social, ambiental e nas voláteis economias dos países em desenvolvimento. O que corrobora para ratificar que crescimento econômico e PIB não representam, necessariamente, desenvolvimento social. Pois desenvolvimento é amplo, contempla a sistematicidade dos seres, da economia, do meio ambiente, sociedade, enfim a plenitude das várias formas de vida.

A finitude dos recursos, valorizados enquanto tal pela moderna sociedade, traz uma nova configuração que tenta encarar a economia e as questões políticas de maneira ecológico-social. “A economia ecológica é um campo de estudos transdisciplinar estabelecido em data recente, que observa a economia como um subsistema de um ecossistema físico global e finito" (Alier 2007: 45). A sustentabilidade da economia implica mudanças na estrutura produtiva e social para tentar equilibrar a pegada ecológica e o nível de consumo $^{2}$ em tempos de globalização.

A pegada ecológica, ou seja, o que é $2_{\text {"Porque nosso padrão de consumo é altamente }}$
predatório. Seguimos barrando rios e fazendo
hidrelétricas, e quando barramos rios, matamos
todo o ecossistema que é dependente do ciclo
hidrológico. Caso o binômio água e energia seja
resolvido, também será resolvido o problema da
emissão de carbono. Quando se resolve a questão
hídrica, recompomos as florestas, as matas
ciliares, a biodiversidade. O fluxo de oxigênio no
ambiente e a própria natureza trabalhará para
reduzir a emissão de carbono. Se não atacarmos
as causas ficaremos circulando em torno das
consequências, sem encontrarmos uma solução
real e eficiente para as presentes e futuras
gerações" (Khalili 2014). necessário ou tido como tal para se viver, energia, alimentos, biomassa, produtos direta e indiretamente originados de matéria-prima natural, tem aumentado consoante novos modelos e padrões de consumo são impostos culturalmente através da mídia e internet. Os padrões culturais refletem na quantidade e qualidade do que é consumido mundialmente. No entanto, não se elenca quais os fortes impactos que são causados pela veloz degradação de recursos para produção e confecção de produtos industrializados ao redor do globo. No século XXI, não há como desconsiderar o direito ao meio ambiente, ou se descartaria o mesmo direito aos demais seres vivos, embora possa ser considerado de natureza culturalmente distinta, dependendo da sociedade, tempo, valores e costumes — sem um tratamento universal, pois, por exemplo, a poluição que ocorre em determinado país passará para o país vizinho. Não há como limitar, sob a lógica do Estado, nenhum dano de matéria ambiental, porque, em se tratando de um sistema global, são sempre danos transfronteiriços (Bello Filho 2002). 
Assim sendo, problemas criados globalmente requerem soluções integradas e conjuntas por parte dos responsáveis solidariamente empresariais, industriais e políticos assim como a de modo compartilhado entre indivíduos e sociedade. O modo de vida local também tem consequências supranacionais. Questões envolvendo água, petróleo, florestas, biodiversidade e outros são temas relevantes na ordem geopolítica mundial. Para isso, o direito internacional ambiental trabalha para que haja uma unicidade nas decisões políticas e na justiça ambiental praticada em todos os continentes.

Conforme salienta o autor a seguir. Em termos pragmáticos, embora tenha por conteúdo a biodiversidade, o direito fundamental ao ambiente natural somente assume contornos definitivos no caso concreto. "Com efeito, como todo direito fundamental, o meio ambiente e suas interfaces se complementam e se delimitam nas relações de reciprocidade com as demais categorias de direitos fundamentais, compreendendo, além da dimensão biológica, também uma dimensão social, histórica, temporal e antropológica” (Silva 2008: 321).

As recorrentes disputas por novos espaços de consumo e fontes mantenedoras de matérias-primas trazem para o palco mundial conflitos latentes, por vezes disfarçados de cunho humanitário ou religioso, as grandes potências mundiais e os países dependentes de tecnologia, devedores das instituições financeiras internacionais, importadoras de produtos industrializados e outros. Nesse sentido, a economia ecológica não é aferida unicamente por números na balança comercial. O novo enfoque considera os indicadores sociais e os índices de desmatamento, reflorestamento, fauna e flora, além das condições climático-ambientais, assim como bem-estar e qualidade de vida no campo e na cidade (Alier 2007).

A junção de interesses públicos e civis, enquanto tomada de decisão pelos políticos e gestores governamentais, deve somar esforços com o meio empresarial para dirimir questões relativas a novos estilos de desenvolvimento e o que é desenvolvimento, para quem serve, ao que estão alinhados e que horizontes coadunados com a sustentabilidade podem ofertar à população. $\mathrm{Na}$ verdade, a oferta de serviços prestados pelo Estado ao cidadão deve ser de forma contínua, segura, em preços acessíveis e com qualidade. Apesar do neoliberalismo e das privatizações, o bem-estar social e a prestação de serviços essenciais ou de ramos que venham a balancear a economia têm figurado como uma nova aurora ou reapropriação social dos meios produtivos e das fontes energéticas.

Nessa linha, o cenário de capacidade estatal em fornecer serviços e bens têm elevado as expectativas de cunho socioambiental para fomentar uma equidade e distribuição da renda proveniente das novas modalidades de demanda sociocultural. Ao se pensar o desenvolvimento como liberdade e essa enquanto possibilidade de realização de escolhas concretas sobre o nível e tipo de vida que as pessoas têm acesso, conforme questões culturais, econômicas, educacionais e outras, são imprescindíveis a prevalência e a afirmação da proteção social na qualidade de meio e fim do desenvolvimento como múltiplo e meio, não o restringindo ao mero sucesso financeiro e acesso a bens de consumo. A proteção social também possibilita um aumento da capacidade de escolhas, sendo que tanto a perspectiva da desmercantilização passam pelo retorno da centralidade da intervenção estatal na provisão, organização e oferta de serviços à população (Andrade \& Zimmermann 2009).

Quanto mais a economia cresce maior será a degradação ecológica, nos moldes do neoliberalismo vigente, maior serão os danos de todas as vertentes. Até porque, a rápida expansão do crescimento da economia determina, nesse veloz regime de exploração, a incorporação de novos territórios visando a obter recursos, fabricação de mercadorias e distribuição de produtos para os mercados consumidores, além de áreas para destinação de resíduos. Exemplificando, novas florestas de eucaliptos ou outra espécie que cresça rapidamente são cultivadas para produzir celulose e funcionar como áreas de absorção do carbono; mangues são destruídos por projetos de carcinicultura de exportação numa escala mais rápida do que o reflorestamento; o petróleo é extraído com maior celeridade não só do que o seu ritmo geológico de formação, como também da capacidade dos ecossistemas locais para assimilar a água usada ao longo do processo produtivo dos combustíveis fósseis e seus derivados, deixando um rastro de outros resíduos nocivos (Alier 2007). 
Os impactos decorrentes da necessidade de utilização de energia e consumo de materiais advindos do processamento de recursos naturais, considerado a pegada ecológica das pessoas, denota a assunção e organização dos pobres para reivindicar seus direitos. Até porque, quem mais sofre com as externalidades socioambientais engendradas pela devastação sistêmica são os menos abastados. Ao ser atingido, geralmente, o povo luta contra a afetação da sua saúde, renda, e condições de vida ${ }^{3}$. O cerne dos custos ambientais é a perpetuidade do sistema capitalista de produção e o êxito da reprodução no tempo e no espaço das ideologias e mitos do progresso infinito e do crescimento econômico como ideal de felicidade.

Ao dizer que as ações antrópicas interferem nos ecossistemas, na vida urbana, no meio ambiente como um todo e, principalmente, na vida das pessoas enquanto seres humanos, tem-se que a sustentabilidade ambiental ${ }^{4}$ deve ser uma luta e conquista diárias. Não pode haver falta de consenso ou coro quando a questão é a luta pela própria continuação da existência sobre a terra, o que
${ }^{3} \mathrm{O}$ que se percebe, em última análise, é que onde não houver respeito pela vida e pela integridade física e moral do ser humano, onde não houver limitação do poder, enfim, onde a liberdade e a autonomia, a igualdade (em direitos e dignidade) e os direitos fundamentais não forem reconhecidos e minimamente assegurados, não haverá espaço para a dignidade da pessoa humana e esta (a pessoa), por sua vez, poderá não passar de mero objeto de arbítrio e injustiças (Sarlet 2008: 35).
${ }^{4}$ Os aspectos da sustentabilidade, questão que põe à prova a coerência diante de necessidades conquistadas graças ao desenvolvimento tecnológico, levam em consideração as questões econômico-sociais e geográficas, consistindo em temática que atinge a todos, indistintamente, há pelo menos 3 (três) décadas. Trata-se da possibilidade de bem utilizar os recursos naturais, necessários para a sobrevivência e melhores condições de vida no planeta, assim tomados os avanços trazidos, notadamente pela Revolução Industrial, e, consequentemente pelo desenvolvimento tecnológico, que assumiu um ritmo galopante nos últimos anos (Cunha 2008 299-300). inclui a qualidade de vida necessária para o bem-estar físico, emocional e transcendental do ser.

A efetividade da sustentabilidade poderia transformar a realidade dos que aprendem uma lógica ou várias lógicas de como trabalhar com a natureza, com o próximo e respeitando os limites do ecossistema. A incorporação das condições ecológicas no dia a dia dos que dependem dos recursos ambientais constituem a harmonia necessária para ter durabilidade em suas propostas de negócios:

\begin{abstract}
O discurso da "sustentabilidade" leva, portanto, a lutar por um crescimento sustentado, sem uma justificação rigorosa da capacidade do sistema econômico de internalizar as condições ecológicas e sociais (de sustentabilidade, equidade, justiça e democracia) deste processo. A ambivalência do discurso da sustentabilidade surge da polissemia do termo sustainability, que integra dois significados: um, que se traduz em castelhano como sustentable, que implica a internalização das condições ecológicas de suporte do processo econômico. Neste sentido, a sustentabilidade ecológica constitui uma condição da sustentabilidade do processo econômico (Leff 2011: 20).
\end{abstract}

Há uma nítida controvérsia no capitalismo atual em que é impossível ser sustentável nos mais diversos sentidos do termo. Pois, a sustentabilidade inviabiliza os conceitos redutores, fragmentados, utilitaristas e economicistas do projeto industrial vigente. Por isso o emergente esfacelamento de costumes, hábitos e ações que não se coadunam com as novas necessidades da humanidade e natureza. As velhas hierarquias estão sendo abolidas para abrirem espaço para novas percepções e tratamentos diferenciados dos componentes ambientais.

Assim, a necessidade urgente de uma superação da lógica do capital, trazendo uma nova práxis da relação sociedade-natureza. A premissa de encontrar horizontes para a vida, com uma transversalidade e interesse em trabalhar interdisciplinarmente novas abordagens científicas. Uma ciência que viabilize novos futuros possíveis:

Racionalidade e irracionalidade da ciência jamais serão uma mera questão de presente e futuro, envolvendo também uma questão de futuros possíveis. Podemos aprender com nossas falhas - isto também quer dizer: uma outra ciência é sempre possível. Não apenas uma outra teoria, e sim uma outra práxis 
dessa relação. Se for correto o que o presente nada mais é que uma hipótese que ainda não pudemos superar, então chegou o momento da contra-hipótese (Beck 2010: 272).

Entrementes, a racionalidade ambiental, sua primazia e relevância para o entendimento dos problemas que assolam os tempos modernos pode ser definida como:

\begin{abstract}
A valorização do patrimônio natural e cultural conduz à construção de uma nova racionalidade produtiva, que incorpora os processos culturais e ecológicos ao processo produtivo, como condição para alcançar um desenvolvimento sustentável. Os princípios e objetivos da racionalidade ambiental introduzem uma série de critérios qualitativos como propósito desta nova estratégia de desenvolvimento (uma distribuição mais equitativa da riqueza, uma maior participação social na tomada de decisões e no controle das atividades produtivas, assim como uma melhora da qualidade ambiental e da qualidade de vida). Além disso, incorpora valores e potenciais produtivos que não podem ser reduzidos a um padrão único de medição, em termos de valores atualizados de mercado: a diversidade de valores culturais, os serviços ambientais dos processos naturais, os processos ecológicos de longo prazo, a solidariedade entre gerações e as preferências dos futuros consumidores (Leff 2009: 166).
\end{abstract}

A relevância da compreensão da racionalidade capitalista e seu contraponto, a racionalidade ambiental, demonstra que a humanidade pode sucumbir em seu modelo depredatório de civilização. A própria sociedade é a responsável por seus inúmeros problemas e cabe a ela encontrar respostas, alternativas, apontar novos caminhos e percorrê-los em busca do elo perdido com o meio ambiente. A propósito, a dialética de saberes que venham a formar uma nova mentalidade na relação sociedade-natureza, traz uma tônica para o mundo e as formas de concebê-lo.

A racionalidade ambiental abre um mundo pleno de muitos mundos por meio de um diálogo de seres e saberes, da sinergia da diversidade e da fecundidade da outridade, de uma política da diferença. Sendo assim, as diferenças e singularidades de cada povo, região, bioma, dentre outros compõem o vasto horizonte de possibilidades de se conviver no planeta de forma mais harmônica. Cada qual com suas características e modos de se perceber o pleno conceito de sustentabilidade, de desenvolvimento humano e, ao mesmo tempo, se autoconhecer. "O pensamento da complexidade ambiental leva assim a compreender o mundo no rumo do ser com a natureza, e do ser com o outro e com o Outro, transbordando a relação de conhecimento entre conceito e real para um diálogo de saberes" (Leff 2009: 22).

Esse mundo visível, com sua fauna, flora, economia e conjuntura social divergente conforme a época e lugar, são paisagens que se formam mediante a transformação da natureza pelos humanos e vice e versa. Novas maneiras de se abordar problemas e questões que necessitam de intervenção humana, já que oriundas do modelo produtivo mundial, são ${ }^{5} \mathrm{~A}$ desigualdade e a invisibilidade caminham possíveis de conversação, de interatividade e $\quad$ lado a lado. A igualdade é uma invenção; é um dialética no que tange aos benefícios e difusão de princípios apreendidos pela civilização ${ }^{5}$.

Nesse diapasão, a questão ecológica é ergueu os homens acima da vida, e desvendoulhes um mundo comum (Arendt 2004: 48).

essencialmente política e ainda que se encontre no país boas razões para se ter aversão à política, a seriedade dos problemas que são levantados exige, por isso mesmo, muita criatividade e lucidez política. Pois, a alternativa é ser mais politizado, mais atuante e exigente em termos de utilização de produtos, serviços e mercadorias (Gonçalves 1996).

As lutas sociais e ambientais têm progredido e, ao mesmo tempo, sido concentradas por quem depende diretamente dos recursos naturais e sofre os efeitos danosos da rápida expansão das bases produtivas. A necessidade de impor limites para frear ou diminuir a devastação socioambiental formataram mecanismos jurídicos, civis e administrativos para restabelecer as mínimas condições e garantias de efetivo exercício dos direitos humanos e ambientais fundamentais. 
Como vários fatores se somaram para possibilitar um retrocesso ambiental, mesmo diante de avanços consideráveis na legislação ambiental, demonstra o potencial da economia e seu crescimento como símbolo do progresso ${ }^{6}$ sendo mito $^{7}$ da perpetuidade essencial para justificar atrocidades contra o povo, fauna e flora do presente e do futuro.

Nesse diapasão, tem-se a emergência de se questionar e revisar os estamentos da civilização ocidental, pois a mesma caminha para a autodestruição. A sociedade de risco também é, nesse sentido, dada a possibilidade, uma sociedade autocrítica porque permite que ela dê um passo atrás e imagine alternativas e saídas. Nela, são sempre coproduzidos pontos de referências e premissas da crítica sob a forma de riscos e ameaças, seja pelo agir, seja pela não tomada de decisão. A crítica do risco não é uma crítica normativa de valores. Os riscos surgem justamente quando tradições e, consequentemente, valores são decompostos. A base da crítica encontra-se menos nas tradições do passado e mais nas ameaças do futuro, justamente pela decorrência de ações tomadas anteriormente que cumuladas ainda não se sabe seus efeitos no meio ambiente. (Beck 2010).

Outrossim, a imiscuidade do poder público com a iniciativa privada, suplanta que os valores da racionalidade instrumental e linear. A articulação do poder econômico em sintonia com políticos desvirtuou os reais interesses e destinatários dos bens ambientais. $\mathrm{O}$ modo escuso de deturpar os conceitos, metodologia e posterior implantação das ferramentas capazes de limitar a expansão desordenada do capitalismo foi penetrar no âmago das discussões sobre uma nova era no campo do desenvolvimento humanitário:

\footnotetext{
Não obstante, antes que as estratégias do ecodesenvolvimento conseguissem vencer as barreiras da gestão setorializada do desenvolvimento, reverter os processos de planejamento centralizado e penetrar nos domínios do conhecimento estabelecido, as próprias estratégias de resistência à mudança da ordem econômica foram dissolvendo o potencial crítico e transformador das práticas do ecodesenvolvimento. Daí surge a busca de um conceito capaz de ecologizar a economia, eliminando a contradição entre crescimento econômico e preservação da natureza. Estratégias de poder e relações político-econômicas reduziram o discurso ambiental crítico, submetendo-o aos ditames da globalização econômica (Leff 2011: 18).
}

Nessa conjectura, a dimensão política é crucial para a derrocada de projetos sustentáveis ou não. A adoção, permissão e autorização por parte do Estado e seus representantes legais são efetivadas através de políticas setoriais e intersetoriais que se entremeiam para dar lastro ao sistema produtivo local e econômico vigentes. É o que diz o fragmento em seguida:

"Hoje é quase impossível negar que uma política econômica que se pretenda tão mais bem sucedida quanto o maior índice de crescimento em PIB alcançado, nos países industrializados mas sobretudo também nos países em desenvolvimento, aceita consciente ou inconscientemente uma exploração predatória do nosso "capital" em natureza, a destruição do meio ambiente, bem como a perda de ecossistemas, de espécies animais e vegetais, de florestas, de solo fértil e de mananciais de água potável” (Leipert 2002: 378). 
A dissimulação por parte dos magnatas econômicos continua a ditar as regras do mercado e de como os estados e nações devem se comportar para continuar inseridos na globalização. Uma engrenagem perfeita para estabilização dos interesses dos poderosos com o aval do Estado e a livre impressão de que as externalidades são aliviadas pelo mero crescimento econômico. Com o avanço da problemática e discussão sobre os temas, além da redemocratização e uma pressão internacional sobre os países detentores de grandes recursos naturais, formou-se um campo propício para estabelecimento de uma proteção legal do meio ambiente.

A título de conhecimento, a imbricada relação entre Estado, indutor, produtor, financiador e fiscalizador dos rumos da economia, sistema produtivo e comércio traz uma lógica de sistema financeiro, política, meio ambiente, sociedade como cenário do cataclisma em que passa o país na contemporaneidade. Como a história é cíclica, esse modelo desenvolvimentista que segrega, exclui e acumula capital e poder para uma minoria que se reinventa para se perpetuar nos dias atuais. Nesse sentido, em tempos passados, a situação era semelhante:

\begin{abstract}
"Entretanto, essa equiparação, totalmente natural, entre crescimento econômico e desenvolvimento econômico e social chegou a seu termo no final da década de 60 e início da década de 70. A essa altura, não se podia mais ignorar que a produção de bens e serviços em permanente elevação não estava apenas ligada a efeitos positivos sobre o bem-estar e a qualidade de vida da população, mas se fazia acompanhar crescentemente os efeitos negativos sobre o meio ambiente natural e sobre a saúde e as condições sociais de vida da população (Leipert 2002: 378)".
\end{abstract}

A gestão do patrimônio público, seja os espaços notadamente urbanos ou os bens ambientais mais remotos, assim como os transformados e já alterados pela dinâmica da sociedade é responsabilidade dos três entes administrativos dos poderes constituídos. Além do poder público, a sociedade tem a sua parcela de responsabilidade e deve cooperar para atingir os fins precipuamente inscritos no ordenamento constitucional:

\begin{abstract}
Colocando em termos simples, a sustentabilidade é prover o melhor para as pessoas e para o ambiente tanto agora como para um futuro indefinido. E através de um desenvolvimento sustentável identificar as dimensões e escalas definindo a amplitude de sua atuação. Enquanto na dimensão política a sustentabilidade é construída através de agentes sociais, que atuam no ambiente sócio-econômico-cultural, recebendo do poder público possibilidades no controle de recursos para decisões políticas. Na escala local, o desenvolvimento encontra na forma participativa de gestão o instrumento de consenso necessário para atuação desses agentes. Tendo como objeto principal a dimensão política da sustentabilidade na escala local, especificamente na elaboração de políticas públicas com o objetivo de uma gestão mais participativa e popular (Reis 2013).
\end{abstract}

A delimitação do que usar, como usar, em que quantidade, onde e em que empregar os recursos oriundos do solo, rios, mar, florestas, dentre outros provêm do Estado. O estado é o responsável pela macro e microestrutura legitimada para delinear os rumos dos investimentos e exploração de recursos naturais. O “comodato ambiental" se trata de contrato social intergeracional, cujos comodatários (gerações presentes) devem restituir os bens ambientais aos comodantes (gerações futuras). Nota-se assim, uma ação e reação da geração atual para com a posterior. A geração atual devendo manter níveis de consumo e utilização compatíveis com a restauração dos estoques de vida e seus constituintes para condicionar o desenvolvimento da geração do porvir (Cunha 2012).

As ciências modernas, inclusive o direito, buscam avançar numa convergência que abranja as outras ciências, visando associar os diferentes conhecimentos para uma compreensão das múltiplas e interdependentes questões e riscos que envolvem a contemporaneidade. Essa interdisciplinaridade tem o objetivo de solucionar os paradigmas que o capitalismo e a vida em 
sociedade cada vez mais urbanizadas e dependentes de recursos trouxeram para ampla discussão e politização.

Neste contexto, a discussão dos assentamentos sobre os quais a sociedade ocidental está assentada. Questionar a própria divisão internacional do trabalho, pensar criticamente acerca os modelos hegemônicos vigentes em torno da forma de geração de riqueza, sua distribuição, suas diversas implicações, são essenciais para problematizar as relações de poder, produção e distribuição de riquezas:

\begin{abstract}
A indiferença diante dos riscos, de todo modo imperceptíveis, que sempre encontra na superação da carência palpável sua justificação - e, na verdade, temna (vide Terceiro Mundo!) - , é o terreno cultural e político no qual os riscos e ameaças florescem, crescem e frutificam. Na sobreposição e concorrência entre as situações problemáticas da sociedade de classes, da sociedade industrial e da sociedade de mercado, de um lado, e aquelas da sociedade de risco, de outro, a lógica da produção de riqueza, dados as relações de poder e os critérios de relevância vigentes, acaba por prevalecer- $e$ justamente por conta disto prevalece no fim das contas a sociedade de risco (Beck 2010: 54).
\end{abstract}

Se é remetido ao conceito de sociedade do risco, de sustentabilidade e possibilidade de outro crescimento, ou quem sabe decrescimento ${ }^{8}$ e modelo civilizatório não pautado única e exclusivamente no desenvolvimento econômico. Essa conjuntura traz à tona um novo horizonte para o urbano e sociedade global. A exemplo disso, tem-se o princípio da precaução inibindo a precipitação, isto é, se não se tem noção do perigo que tal atividade pode causar, então se apresenta o risco e a atividade deve ser evitada. É uma maior conscientização que a pressão humana exerce sobre o meio ambiente. Por isso, o princípio da precaução consiste em dizer que não somente somos

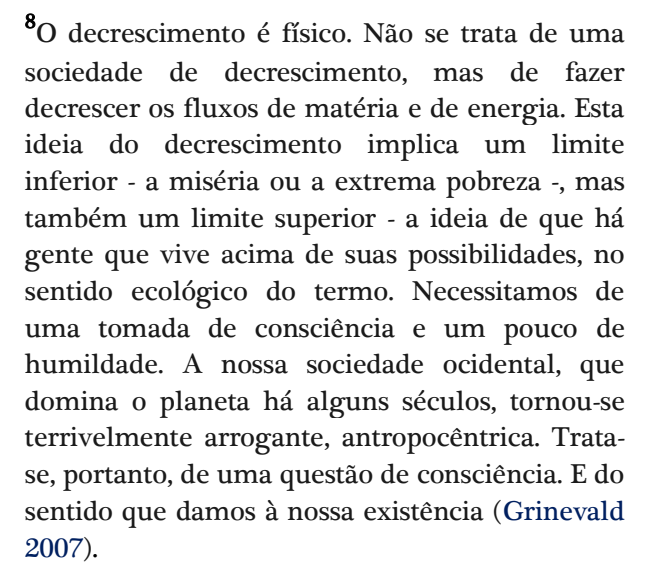

${ }^{8} \mathrm{O}$ decrescimento é físico. Não se trata de uma sociedade de decrescimento, mas de fazer decrescer os fluxos de matéria e de energia. Est ideia do decrescimento implica um limite inferior - a miséria ou a extrema pobreza -, mas também um limite superior - a ideia de que há gente que vive acima de suas possibilidades, no sentido ecológico do termo. Necessitamos de domina o planeta há alguns séculos, tornou-se terrivelmente arrogante, antropocêntrica. Tratasentido que damos à nossa existência (Grinevald 2007).

responsáveis sobre o que nós sabemos, sobre o que nós deveríamos ter sabido, mas, também, sobre o que nós deveríamos duvidar (Lavielle in Machado apud Cunha 2012).

Em outras palavras, a elaboração normativa possibilita uma reestruturação do Estado para afirmar e contribuir com uma sociedade mais equânime e menos agressiva com o meio ambiente. A configuração de novas plataformas de desenvolvimento, de formas de crescimento que comportem o ambiental, social e econômico é possível dentro de uma nova era de pleno êxito humano. Isso quer dizer que é imprescindível, para a eficácia do desenvolvimento sustentável, coibir a geração dos riscos, pois esses podem ser encarados como indícios de danos (Cunha 2012: 236).

Logo, conhecimento e compartilhamento de educação ambiental, de tecnologias limpas, de novas experiências em campos da agricultura, pecuária, recursos humanos e geração de energia e produção de mercadorias vêm conciliar o exponencial crescimento humano com a diminuição de passivos ambientais e sociais. A nova economia se pauta por um crescimento que compatibilize as externalidades. A internalização dos custos ambientais e sociais para a amortização de agressões ecológicas é o novo filão no século XXI.

Para a fixação dessa nova revolução social, uma das estratégias é a formação do ser que compõe tal cenário. Nessa perspectiva, a difusão da internet, a proliferação e acesso à informação e conhecimento, trouxe uma nova abordagem para a educação ambiental ${ }^{9}$. Consubstanciado nisso, políticas ambientais estão em curso para tentar dar respostas e apontar possíveis soluções e alternativas para as mudanças climáticas e seus efeitos.

As políticas ambientais e alternativas que podem contribuir para conservação e uso sustentável dos recursos da Caatinga são diversos, dentre eles: manejo integrado e sustentável 
para produção de madeira e de produtos nãomadeireiros como umbu, pequi, babaçu, fitoterápicos, mel de abelhas nativas. Além disso, some-se o incentivo por parte de universidades, centros de pesquisa, ONG's, que visam conhecer, diagnosticar, compreender e traçar estratégias de convivência, adaptação, uso sustentável dos recursos da Caatinga na região semiárida (MMA 2020).

As políticas ambientais devem ser eficientes e efetivas diante das mudanças

climáticas, dentre elas, Áreas protegidas, recuperação de áreas degradadas e ordenamento territorial, Aprimoramen to da gestão de políticas públicas de conservação da biodiversidade, educação ambiental, financiamento e incentivos econômicos para conservação, geração de conhecimento e formação de recursos humanos (Tabarelli \& Silva 2003).

\section{Políticas ambientais diante das mudanças climáticas}

A sociedade está despertando para os problemas de ordem antrópico e ambiental. Isto provoca uma preocupação do direito e dos investimentos públicos em perfilar os investimentos público direcionando para a sustentabilidade. Logicamente, há uma narrativa do antropoceno e suas nuances que confirmam ou renegam a responsabilidade da humanidade na alteração climática. As soluções e possíveis criações que venham a eliminar os efeitos nocivos da rápida industrialização, da veloz urbanização, da crescente demanda por matéria-prima e recursos ambientais e energéticos têm contribuído para a fixação de uma educação moldada em conceitos sustentáveis, igualdade de gênero e raça, respeito a minorias, eliminação da pobreza, dentre outros. Se para a racionalidade ambiental do planeta se requer cidadãos conscientes e preocupados com as questões que os cercam, a educação ambiental teria como um devir, um sentido deontológico- do vir a ser consoante as mudanças e condições para sua transformação, obviamente, não como panaceia para salvação do mundo a tônica de cumprir vários preceitos constitucionais.

As políticas ambientais diante das mudanças climáticas estão passando por uma transformação de ordem política, econômica e jurídica. Em que pese a dinâmica da intensificação das ondas de calor, das secas e estiagem, das chuvas excessivas, dentre outros fatores naturais que estão se mostrando atípicos e moldando o futuro do planeta. Se a pauta do dia é a ordem climática e segurança alimentar, as questões envolvendo sustentabilidade, energia e mecanismos que venha obstar esse cenário de alterações climáticas intensificados pela atual conjectura antrópica.

Nesse sentido, mudanças climáticas, conforme o trecho abaixo ajuda a esclarecer:

As mudanças são cumulativas quando resultantes do acréscimo de mudança localizadas, em sistemas naturais, como a destruição de habitats, a perda da biodiversidade, os desflorestamentos, a desertificação e as mudanças nos padrões de assentamentos humanos. Essas são também consideradas globais porque seus efeitos são mundiais, mesmo que as causas possam ser localizadas (Turner apud Dias 2002: 74).

Ou seja, nota-se uma fragilidade global no que concerne as alterações climáticas. Isso porque, em sendo sistemática, a pressão exercida pelos países mais poluentes e consumidores de recursos naturais e energéticos extrapolam as capacidades de renovação dos estoques naturais. Um ciclo de pobreza, geração de miséria e injustiça ambiental nos países que ficam assolados com a destruição de suas florestas e habitats para dar vazão ao imperialismo mundial. A acumulação das agressões ambientais ao longo de anos, intensificadas pelas ações e práticas humanas trazem um caótico panorama de proporções globais. Claro que a ser sentida, 
primeiramente, pelos mais pobres e países do eixo Sul, justo os que vendem seus recursos a preços ínfimos para saciar as multinacionais e mercado de commodities:

\begin{abstract}
A atmosfera, a biosfera, a geosfera e a hidrosfera são sistemas ambientais (incluem sistemas de troca gasosa atmosférica, dinâmica biogeoquímica, circulação oceânica, interações entre populações etc.). Os sistemas econômicos, políticos, culturais e sociotecnológicos - chamados de noosfera ou antroposfera - são os sistemas humanos. O estudo das mudanças globais busca entender como os sistemas ambientais em nível global afetam ou são afetados pelas mudanças ocorridas em qualquer um desses sistemas ou esferas. Para esse autor o ponto crucial desses estudos é o entendimento dos mecanismos de retroalimentação (feedback) entre os subsistemas que amplificam ou enfraquecem os impactos iniciais (Peccatiello 2011: 74).
\end{abstract}

Para complementar o raciocínio, veja-se:

O clima é um sistema complexo, regulado por múltiplas interações entre a atmosfera, o oceano, a hidrosfera, a criosfera e a biosfera. Tal sistema tem sofrido, desde a constituição da atmosfera terrestre, alterações em diferentes eras geológicas, visto que está em constante e permanente transformação (dinamicidade), assim como os demais sistemas da natureza. As atividades vulcânicas emitem, por meio das erupções, uma grande quantidade de gases e cinzas à atmosfera, que afetam o equilíbrio climático de todo um hemisfério, principalmente os processos de absorção, transmissão e reflexão de energia solar. Desta forma, os vulcões são uns dos elementos essenciais para os estudos das mudanças climáticas (Teodoro \& Amorim 2008: 27-28).

Logo, vê-se que os sistemas ambientais e humanos fazem trocas, são dinâmicos e interagem entre si. Mesmo que a quantidade e qualidade das ações humanas ${ }^{10}$ não possam ser medidas em sua totalidade, por causa do princípio da precaução e teoria do risco, deve-se procurar mitigar ou eliminar os impactos provocados pelas indústrias, fábricas, sistema produtivo local e mundial, modo de produção capitalista, dentre outros. Devido à complexidade que envolve a vida na Terra, seus ciclos, fenômenos, processos e sistemas de retroalimentação e feedback.

O princípio da precaução enseja que, no caso de conflito, a incerteza, a insegurança no cuidado com o patrimônio ambiental a visão jurídica que possa agir com cautela e em caso de dúvida que provoque danos irreparáveis ou insanáveis, se julgue in dubio pro natura. Assim, o princípio visa proteger, de modo integral a tutela jurídica do meio ambiente em situações de impactos socioambientais que afetem o meio ambiente e o equilíbrio ecológico interferindo de modo negativo nas condições que propiciam a teia da vida (STJ 2019).

No Brasil, as mudanças climáticas são acentuadas por um longo processo histórico que excluiu milhares de pessoas do acesso à terra, água, emprego, educação, saúde e moradia. Além de um contexto político, social e econômico desvantajoso para a maioria da população, uma ampla parcela ainda sofre com os estigmas das injustiças ambientais. Se ser pobre já é um fator agravado pelas secas, enchentes, inundações, fome, acesso a água potável, energia elétrica e outros, imagine-se ser pobre, oprimido e excluído do circuito das maravilhas do século XXI e suas tecnologias.

Pensando nisso, após a Conferência da Eco 92, o governo brasileiro adotou a Agenda 21. Marco da ONU para o regionalismo brasileiro, as medidas e objetivos da agenda foram assinados 
dez anos depois do evento sobre desenvolvimento sustentável no Rio de Janeiro. Segundo a Agenda 21 brasileira, editada em julho de 2002, com uma grande preocupação em efetivar a síntese entre o ambiental e o urbano e, para tanto, busca orientar as políticas ambientais, transmitindo-as do nível nacional para o estadual e municipal, concretizadas através de planos e regulamentos (Peccatiello 2011).

Fica evidente a necessidade de participação dos gestores políticos locais. $\mathrm{O}$ envolvimento dos agentes públicos municipais e estaduais para implementação efetiva dos conceitos abordados pela Agenda 21 nacional. Sem o engajamento de prefeitos, governadores, secretários e todos os envolvidos na "máquina pública" aliados a sociedade civil organizada, os ditames da Agenda 21 nacional, quiçá os Estados e municípios que a têm, serão apenas mais um documento sem eficácia para a vida do cidadão. Além disso, devido ao fenômeno da ampla urbanização e seus efeitos danosos devido à expansão desorganizada, deu-se um contorno para a Agenda 21 mais voltada para os problemas socioambientais das grandes, médias e pequenas cidades (Peccatiello 2011).

Nesse diapasão, um dos domínios fitogeográficos mais frágeis e desprotegidos é a Caatinga. Isso devido não apenas a ação antrópica ${ }^{11}$ tais como desmatamento, criação extensiva de animais, retirada da vegetação para diversos usos e fins, mas agora pela intensificação dos potenciais efeitos das mudanças climáticas. É o que está relatado abaixo:

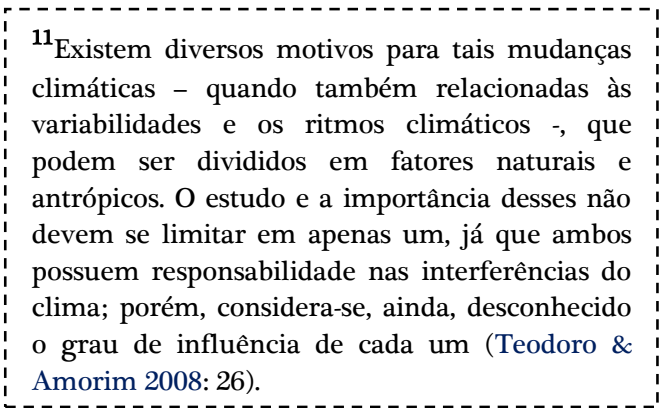

A Caatinga é um dos domínios fitogeográficos brasileiro mais vulnerável às mudanças climáticas e tende a ser o mais atingido pelos efeitos negativos do aquecimento global, que pode agravar o quadro da desertificação e reduzir as áreas aptas para a agropecuária e a capacidade de geração de serviços ambientais, com impactos severos também na disponibilidade de recursos hídricos na região (Declaração da Caatinga 2012: 1).

As políticas ambientais brasileiras ainda são incipientes diante da demanda crescente. A degradação que se verifica no semiárido vem provocando inúmeros distúrbios alimentares, financeiros, sociais e ambientais. Sendo assim, o quadro da situação no geral é preocupante. O risco de desertificação, grandes áreas já desertificadas e outras em processo grave de desertificação, colapso para os recursos hídricos, terras inférteis e êxodo rural. O lugar enquanto paisagem e território transformado pelo sujeito está se tornando inapto para sua permanência digna.

Ante o aumento das secas, da expansão da desertificação e o consequente agravamento de uma situação já calamitosa, tem-se que:

\footnotetext{
A política de combate às secas adquire foros institucionais, federais e a política de açudagem é formulada desde o início do século, já com um direcionamento claro para beneficiar proprietários, restringindo o acesso à população mais necessitada, tais os "requisitos" exigidos na construção das obras. Se examinamos os números contidos no trabalho, sobre o número de açudes particulares no remoto ano de 1909, fica a velha pergunta sempre presente: "com tanto açude, e por que não se resolve a questão da seca no Nordeste?"; mas a resposta está nos próprios números: a privatização da água (Ferreira 1993: 10-11).
}

Se historicamente ${ }^{12}$ há um enorme contingente de verbas e auxílios para os problemas já corriqueiros do Nordeste, por que até hoje os mesmos se repetem? A questão da privatização da água mostra que também há outras questões mais arraigadas, tais como a prevalência de interesses político-partidários em manter um povo alienado e dependente. Até porque, com as ajudas emergenciais, cada vez maiores, é possível desviar mais recursos e perpetuar a supremacia político-econômica dos detentores do cabedal ideológico necessário. 
$\mathrm{Na}$ tentativa de instituir um contínuo programa de convivência com o semiárido e quebrar as barreiras do assistencialismo somente em tempos de crise de abastecimento, foi criada a Declaração da Caatinga. Nela, as características e especificidades da Caatinga e seu domínio fitogeográfico inserido no semiárido são elevados por sua importância para a região e para o Brasil. Além disso, um marco civil e jurídico tende a se ${ }^{12}$ O Nordeste, com seus produtos em crise, não
conseguia nenhuma medida protecionista e
passou a se utilizar dos períodos de estiagem
para reivindicar ajuda financeira da União. Para
conseguir apoio federal, o Sul alegava café; o
Nordeste, a seca- cada um à sua maneira e com
seus argumentos. Além da crise no açúcar e
algodão, em termos de Nordeste (Ferreira 1993:
30-31).

formar para enaltecer a importância da inclusão na Constituição Federal a Caatinga. A gestão correta, o acompanhamento constante e permanente das necessidades do ecossistema em questão é fundamental para a substancial resolução de seus percalços.

Tanto que, nas palavras do documento firmado entre especialistas, professores, pesquisadores, políticos e outros atores sociais está definido que:

\begin{abstract}
Não obstante os avanços no desenvolvimento socioeconômico da região Nordeste, o uso sustentável e a conservação dos recursos naturais da Caatinga continuam como metas distantes e ainda restam grandes barreiras para a elevação do nível de prioridade com esses temas e consequentes lacunas sistêmicas na implementação de compromissos e políticas que garantam a sustentabilidade desse domínio fitogeográfico. Há enormes desafios para se reduzir a pobreza, promover a mitigação e a adaptação às mudanças climáticas e alcançar os Objetivos de Desenvolvimento do Milênio (Agenda 2030). O esforço em busca da sustentabilidade na Caatinga deve contemplar a implementação e integração de políticas que incluam, entre outras, instrumentos regulatórios, econômicos e fiscais, investimento em infraestrutura, incentivos financeiros e parcerias (Declaração da Caatinga 2012: 2).
\end{abstract}

Logo, a questão das mudanças climáticas tem um peso crucial em torno dos investimentos governamentais. Seja por causa de políticas públicas que possam induzir ao avanço do desenvolvimento socioambiental, ou ainda, por causa da sustentabilidade no semiárido, práticas de convivência, assimilação e difusão de conteúdos e conceitos de educação ambiental ${ }^{13}$ voltada para a realidade local. $\mathrm{O}$ regionalismo da Caatinga, seus benefícios e importância enquanto fonte de renda e geração de divisas podem ser atrativos e úteis para mitigas ou eliminar com as injustiças ambientais, basta dinamizar o potencial gerador de conhecimentos que agreguem valor aos produtos e serviços locais. Isso, indubitavelmente, trará um uso mais sustentável dos recursos da região da Caatinga e seu entorno, assim como, efetivar o alcance dos objetivos do milênio ${ }^{14}$.

\section{Interesse público e função do Estado no controle e gerenciamento da desertificação}

Vários fenômenos de cunho

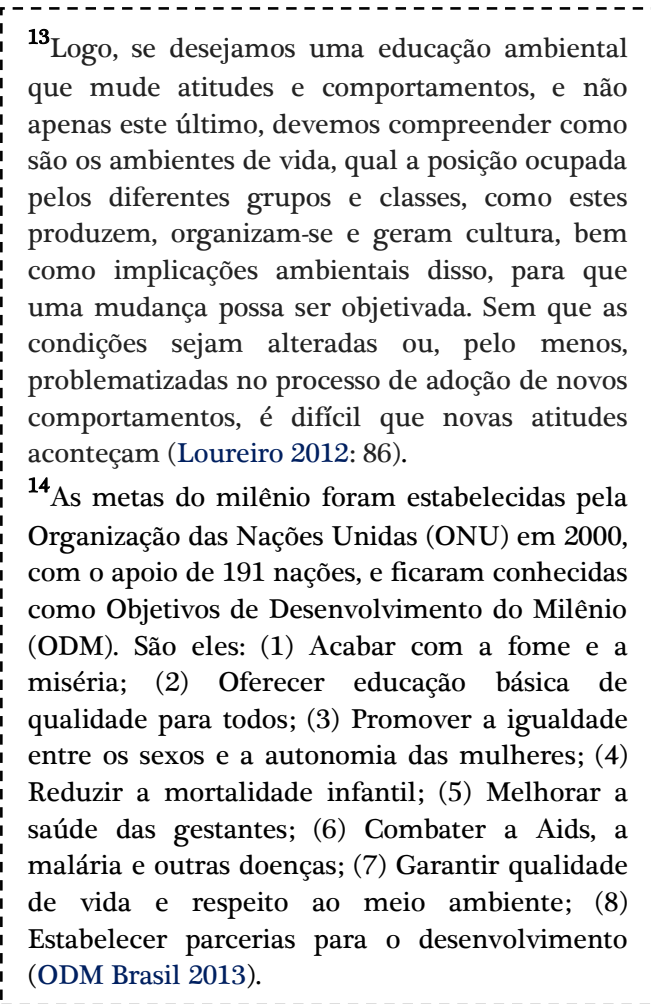

${ }^{13}$ Logo, se desejamos uma educação ambiental que mude atitudes e comportamentos, e não apenas este último, devemos compreender como produzem, organizam-se e geram cultura, bem como implicações ambientais disso, para que ma mudança possa ser objetivada. Sem que as comportamentos, é difícil que novas atitudes aconteçam (Loureiro 2012: 86).

${ }^{14}$ As metas do milênio foram estabelecidas pela Organização das Nações Unidas (ONU) em 2000, (ODM). São eles: (1) Acabar com a fome e a miséria; (2) Oferecer educação básica de qualidade para todos; (3) Promover a igualdade saúde das gestantes; (6) Combater a Aids, a malária e outras doenças; (7) Garantir qualidade Estabelecer parcerias para o desenvolvimento (ODM Brasil 2013).

multidisciplinar puderam se manifestar, ao longo da história do semiárido brasileiro. É o caso da desertificação, que perante uma zona predisposta, ação humana, solo frágil, e intempéries do clima deu origem aos núcleos de desertificação. Além dos núcleos há também outras regiões onde o processo de origem antrópica se manifesta de forma mais branda ou menos severa. 
Nesse contexto, o crescimento populacional, a ocupação desordenada e retirada da Caatinga de forma desenfreada, somado a outros impactos causados pela intervenção humana veio a originar a degradação das terras secas em região passível de sofrer com desertificação em seus variados graus e impactos. Nesse diapasão, é oportuno relembrar que a desertificação é essencialmente o resultado de intensa exploração dos recursos naturais, que tem conduzido à degradação dos solos (erosão hídrica e eólica e perda da capacidade de fertilidade) e, desta forma, contribuído, igualmente, para a diminuição da quantidade e qualidade da água potável, para além da destruição progressiva do coberto vegetal (floresta autóctone e água potável).

Dessa maneira, direitos humanos e ambientais são suprimidos. A instalação do fenômeno desertificação traz manifestamente um problema de ordem ambiental, econômico, social, político e jurídico. Tanto que a intensificação de problemas de ordem socioambiental é alavancada com a seca e desertificação. Problemas de cunho permanente, já que os mesmos levam as pessoas a migrarem de suas terras para pequenas e médias cidades. As consequências são diversas, pois a produção agrícola fica comprometida, falta moradia suficiente e adequada para os migrantes, enfim uma série de prejuízos advindos de uma errônea e excessiva intervenção do sistema econômico vigente e da forma de organização social da humanidade na natureza. Assim, isto que pode ter como consequência o desencadear de migrações e $o$ despovoamento de determinados territórios (Roxo \& Neves 2010: 18).

Com isso, vê-se que o fenômeno afronta o princípio da supremacia do interesse público na proteção do meio ambiente, garantia do desenvolvimento econômico e social ecologicamente sustentável, função social e ambiental da propriedade, prevenção dos danos e degradações ambientais que são concisos em abarcar o domínio fitogeográfico da Caatinga. Além do mais, a questão da problemática que envolve o semiárido é complexa, porém não impossível de ser resolvida. Os elementos essenciais, como terra fértil e produtiva, acesso a água, recursos técnicos e financeiros para fomentar a produção e fixação de pessoas no campo. No entanto, em relação à água, o que se nota é um drama que flagela os pequenos agricultores e produtores familiares é o não acesso a um bem único. Quanto ao uso do bem ambiental na legislação nacional, a lei $\mathrm{n}^{\mathrm{o}}$ 9.433/97 prescreve em seu artigo 11 que "o regime da outorga de direitos de uso de recursos hídricos tem como objetivos assegurar o controle quantitativo e qualitativo dos usos da água e o efetivo exercício dos direitos de acesso à água" LEI no 9.433/97.

$\mathrm{O}$ Estado enquanto ente dotado de poder normativo, correcional, de polícia e administrativo, desde que agindo dentro da legalidade, tem o dever indisponível de manter a ordem pública e institucional, principalmente, em face do interesse público e social. Diante disso, advém que o Poder Público, em seus três níveis, se rege pelos princípios do direito ambiental. Nesse diapasão, a intervenção, regramento e controle das ações humanas que, direta ou indiretamente, podem trazer riscos à incolumidade pública e manutenção dos padrões ambientais, vêm agir para efetivamente tutelar os bens ambientais. Diante do exposto, leia-se o que diz o excerto abaixo:

Também denominados instrumentos de regulação direta, eles objetivam alcançar as ações que degradam o meio ambiente, limitando ou condicionando o uso de bens, a realização de atividades e o exercício do poder de polícia dos entes estatais e, como tal, manifesta-se por meio de proibições, restrições e obrigações impostas aos indivíduos e organizações, sempre autorizadas por normas legais (Barbieri 2007: 72).

Ainda nesse sentido, o fragmento a seguir evidencia o conceito de poder de polícia:

Art. 78. Considera-se poder de polícia atividade da administração pública que, limitando ou disciplinando direito, interesse ou liberdade, regula a prática de ato ou abstenção de fato, em razão de interesse público concernente à segurança, à higiene, à ordem, aos costumes, à disciplina da produção e do mercado, ao exercício de atividades econômicas dependentes de concessão ou autorização do Poder Público, à tranquilidade pública ou ao respeito à propriedade e aos direitos individuais ou coletivos (Redação dada pelo Ato Complementar $n^{0} 31$, de 28.12.1966) (Código Tributário Nacional). 
Logo, se o Estado tem o condão de regular ações que possam causar dano ao meio ambiente, deve condicionar ou limitar o direito de uso, usufruto, disposição, exploração, venda e comércio de bens, serviços ou recursos que potencialmente venham prejudicar o estado natural de equilíbrio ambiental, ainda mais em regiões de instabilidade hídrica. Tanto que para isso ele dispõe do poder de polícia e de instrumentos administrativos e civis, multas e disposições legais de forma coercitiva que obstem a exploração desordenada ou uso abusivo de recursos naturais.

Retomando a questão dos recursos hídricos disponíveis para consumo humano, é notório que a demanda pelo bem cresce e que as fontes estão cada vez mais poluídas. Ademais, no semiárido nordestino a disponibilidade hídrica é menor que em outras regiões do país, como o Norte, por exemplo. Some-se a isso o número de habitantes da região Nordeste e o consumo de água potável, cada vez maior. Diante das exigências e necessidades de uma população que ascende socialmente e demanda maiores fontes de um recurso tão sublime, como o direito ambiental rege essa sistemática? Uma possível resposta, que traz outros questionamentos, pode ser elencada a seguir:

\footnotetext{
Os estudos elaborados pela ANA (Conejo 2005 apud Santana 2007: 56) como subsídio para a criação do PNRH avaliaram a relação demanda-disponibilidade de água nas doze Regiões Hidrográficas Brasileiras. Os resultados mostram que o Brasil é rico em termos de disponibilidade hídrica, mas apresenta uma grande variação espacial e temporal das vazões. As bacias localizadas em áreas que apresentam uma combinação de baixa disponibilidade e grande utilização dos recursos hídricos passam por situações de escassez e estresse hídrico (Santana 2007: 56).
}

O semiárido nordestino se enquadra justamente na que dispõe de baixa quantidade de recursos hídricos e uma alta demanda. Sem contar as baixas precipitações, muitas vezes, esparsas ou acentuadas em poucos dias do ano. Esses fatores que levam ao extremo as condições impostas pela pluviometria, alta evaporação, dentre outros acaba por impor um regime de racionalidade quando se trata de utilização de água doce. Com a imbricada síntese da desertificação, independente de ser uma forma de degradação das terras, fenômeno climático e ambiental, ou condicionado pela ação humana em um solo frágil e desprotegido, a situação entorno da água é crítica. Seu acesso, distribuição, uso e volume são, na maioria das vezes, usados com fins econômicos, eleitorais, ou por uma parcela que têm condições de extrair e pagar pelo precioso bem com fim agroexportador.

Mesmo sendo um fator não condicionante do desenvolvimento local, tendo em vista os citados países e regiões localizados em zonas áridas e, que, no entanto, conseguem lidar com seu sistema hídrico e regime de chuvas de maneira satisfatória. O modo como os seres humanos tratam o recurso em outros lugares reflete uma mentalidade política, histórica e cultural diferente da realidade brasileira. Todavia, é possível afirmar que tecnologias sociais acessíveis a maioria dos pequenos produtores rurais, agricultores familiares e demais moradores do semiárido podem tornar prática corriqueira. A experiência e pleno relacionamento dos humanos com o seu lugar evidencia que soluções e alternativas existem, o que falta é uma maior consolidação e difusão desses mecanismos de convivência com a Caatinga em períodos de estiagem.

\section{Considerações finais}

Há uma construção social e científica que se alinham no tocante ao cuidado com o outro, com o próximo, consigo mesmo e com a própria Terra. O ambientalismo presente se preocupa com o meio ambiente, com as minorias, com os excluídos dos países periféricos, com o empobrecimento das pessoas nos países desenvolvimentos, com a dinâmica desigual das trocas entre os países do Hemisfério Norte e os do Sul.

A assunção dos problemas advindos da revolução industrial, da própria extração e consumo massivo de combustíveis fósseis, da sociedade de massas implica num aumento exponencial dos impactos ambientais negativos. 
A crise climática conduz a aumento do nível dos oceanos, da acidificação dos mares, a elevação do nível da água e problemas para cidades costeiras, a própria salinização de fontes de água doce, aumento de chuvas torrenciais em curto espaço de tempo, concentração de secas e crescimento de sua duração, aniquilação de espécies e extermínio das condições para a própria reprodução e existência da vida.

Toda essa sorte de implicações da forma como a sociedade se projeta tem provocando e acentuando vulnerabilidade socioambiental, isso convoca o direito a se reposicionar, a se criar direitos que possam incluir e cumprir o in dubio pro natura, baseado no princípio da precaução.

O panorama cultural hodierno pressupõe a antítese entre sociedade e crescimento econômico, modelo desenvolvimentista disseminado ao redor do globo que traz sérias consequências para a Terra como um todo. Com fulcro no modelo de produção atual, no retorno econômico de modo acrítico, sem mensurar os impactos presente, futuro e aqueles desconhecidos. A sociedade de risco ignora suas próprias contradições e os sinais já mencionados de extremos de calor, de ondas de frio, de enchentes, aumento e potência de furacões, tufões e tornados.

Nesse panorama, é mais que crucial um arcabouço jurídico-legal e a instituição de políticas públicas que contraponham as mudanças climáticas. Tais políticas públicas podem ser de natureza administrativa, de ordem legal e incidir na recuperação ambiental, na pesquisa e aplicação em prol de manutenção e convívio da espécie humana com os demais seres vivos.

O recorte geográfico do semiárido, como espaço político delimitado devido a características físicas, biológicas e climáticas para ações de fixação e convívio durante as recorrentes estiagens e secas, foi pensado como uma região que engloba várias Caatingas. Várias, pois são únicas, múltiplas e singulares, com zonas de espécies endêmicas e faixas de transição, algumas com pontos de brejo, brejo de altitude, interseção com a mata Atlântica ou com a Floresta Amazônica.

Assim, a relevância de trazer para o enfoque da crise ambiental e os impactos das mudanças climáticas, como o exemplo da desertificação, pautando-se por pontuar os impactos na Caatinga e suas variadas formas de vida. Nesse mote, as ações antrópicas retroalimentam as implicações e externalidades negativas da sociedade de risco, acentuando problemas de ordem climática, de uso e gestão do solo, de disponibilidade de recursos hídricos, e da própria alteração climática com acentuado aumento da temperatura. Não obstante, impossibilitando a continuidade e diversidade da existência das mais diversas formas de vida.

\section{Agradecimentos}

O primeiro autor agradece a Coordenação de Aperfeiçoamento de Pessoal de Nível Superior (CAPES) pela concessão da bolsa e ao "Grupo de Pesquisa Saberes Ambientais e Culturais: Estudos em Homenagem a Enrique Leff - Direito, Sustentabilidade, Impactos, Racionalidades e outros Olhares" pelas interações, debates, discussões e todo o aporte teórico. Aos avaliadores pela revisão crítica que ajudou a melhorar o manuscrito.

\section{Referências}

Agenda (2030) Transformando Nosso Mundo: A Agenda 2030 para o Desenvolvimento Sustentável. Disponível em: https://nacoesunidas.org/pos2015/agenda2030/ (Acessado em: 10/03/2020).

Alier J.M. (2007) O ecologismo dos pobres: conflitos ambientais e linguagens de valoração. São Paulo: Contexto. 379 p.

Andrade F.F. \& Zimmermann C.R. (2009) Desenvolvimento e proteção social (p. 55-79). In: Xavier E.D. \& Santos G.R. (Orgs). Desenvolvimento social em perspectiva. Belo Horizonte: Sografe. $256 \mathrm{p}$.

Arendt H. (2004) Responsabilidade e julgamento. São Paulo: Companhia das Letras. 376 p. 
Barbieri J.C. (2007) Gestão ambiental empresarial: conceitos, modelos e instrumentos. $2^{\circ}$ edição. São Paulo: Saraiva. 386 p.

Beck U. (2010) Sociedade de Risco: rumo a uma outra modernidade. São Paulo: 34.384 p.

Bello Filho N.B. (2002) Efetividade da ação civil pública na defesa do meio ambiente. III Seminário Internacional de Direito Ambiental. Conselho da Justiça Federal, Centro de Estudos Judiciários. Brasília: CJF.

Brasil. Lei $\mathrm{n}^{0}$ 9.433/97. Disponível em: http://www.planalto.gov.br/ccivil_03/LEIS/L9433.htm (Acesso em 29/05/2020).

Cunha B.P. (2008) Direitos humanos e meio ambiente: questões sobre a colheita e a queima do bagaço da cana-de-açúcar no Brasil. Verba Juris, 7(7): 289-322.

Cunha B.P. (2012) Temas fundamentais de direito e sustentabilidade socioambiental. Manaus: Cultura. $246 \mathrm{p}$.

Declaração da Caatinga (2012) Declaração da Caatinga. Documento assinado por ocasião da I Conferência Regional de Desenvolvimento Sustentável do Bioma Caatinga - A Caatinga na Rio+20, realizada nos dias 17 e 18 de maio de 2012. Disponível em: https://www.bnb.gov.br/desenvolvimento-regional/-/asset_publisher/9js6bgNLFaBr/content/dec laracao-da-caatinga/22492?inheritRedirect=false (Acessado em 20/02/2019).

Dias G.F. (2002) Pegada Ecológica e sustentabilidade humana. São Paulo: Gaia. 264 p.

Dupas G. (2012) Progresso: como mito ou ideologia. Cadernos IHU Ideias, 77: 1-35.

Ferreira L.F.G. (1993) Raízes da Indústria da seca: o caso da Paraíba. João Pessoa: Universitária.

Gonçalves C.W.P. (1996) Os (des)caminhos do Meio Ambiente. São Paulo: Contexto. 152 p.

Grinevald J. (2007) O decrescimento é uma questão de consciência. Disponível em: http://www.ihu.unisinos.br/noticias/noticias-arquivadas/7218-\%60o-decrescimento-e (Acessado em 10/09/2013).

Leff E. (2009) Ecologia, Capital e Cultura: a territorialização da racionalidade ambiental. Petrópolis: Vozes. $440 \mathrm{p}$.

Leff E. (2011) Saber ambiental: sustentabilidade, racionalidade, complexidade, poder. $8^{\circ}$ edição. Petrópolis: Vozes. 494 p.

Leipert C. (2002) Custos ecológicos do impacto da economia e cálculo geral da economia nacional. In: Ab'Saber A.N. \& Plantenberg C.M. (Orgs). Previsão de impactos: O Estudo de Impacto Ambiental no Leste, Oeste e Sul: Experiências no Brasil, na Rússia e na Alemanha. $2^{\circ}$ edição. São Paulo: EDUSP. 573 p.

Loureiro C.F.B. (2012) Sustentabilidade e educação: um olhar da ecologia política. São Paulo: Cortez. 128 p.

MMA (2020) Caatinga. Brasília: MMA. Disponível em: https:/www.mma.gov.br/biomas/caatinga (Acessado em 02/05/2020).

ODM Brasil (2013) Objetivos do Milênio -ODM Brasil. Disponível em: http://www.odmbrasil.gov.br/os-objetivos-de-desenvolvimento-do-milenio (Acessado em 30/07/2013).

Peccatiello A.F.O. (2011) Políticas públicas ambientais no Brasil: da administração dos recursos naturais (1930) à criação do Sistema Nacional de Unidades de Conservação (2000). Desenvolvimento e Meio Ambiente, 24: 71-82.

Reis G. (2013) Sustentabilidade, muito além da questão ambiental. Disponível em: http://www.ihu.unisinos.br/noticias/525964-sustentabilidade-muito-alem-da-questao-ambientalartigo-de-gelma-reis (Acessado em 10/05/2020).

Roxo M.J. \& Neves B.M.A. (2010) A percepção do fenômeno da desertificação em Portugal e no Brasil: a importância de informar a sociedade (p. 9-27). In: Moreira E. \& Targino I. (Orgs). Desertificação, desenvolvimento sustentável e agricultura familiar: recortes no Brasil, em Portugal e na África. João Pessoa: UFPB. 344 p.

Santana M.O. (2007) Atlas das áreas suscetíveis à desertificação do Brasil. Brasília: MMA. 134 p.

Sarlet I.W. (2008) As dimensões da dignidade humana: uma compreensão jurídico-constitucional aberta e compatível com os desafios da biotecnologia. In: Sarlet I.W. \& Leite G.S. (Orgs). Direitos Fundamentais e biotecnologia. São Paulo: Método. 368 p. 
Silva R.P. (2008) O direito fundamental ao ambiente natural (p. 301-324). In: Sarlet I.W. \& Leite G.S. (Orgs). Direitos Fundamentais e biotecnologia. São Paulo: Método. 368 p.

STJ (2019) In dubio pro natura: mais proteção judicial ao meio ambiente. Disponível em: http://www.stj.jus.br/sites/portalp/Paginas/Comunicacao/Noticias/In-dubio-pro-natura-maisprotecao-judicial-ao-meio-ambiente.aspx (Acessado em 31/05/2020).

Tabarelli M. \& Silva J.M.C. (2003) Áreas e ações prioritárias para a conservação da biodiversidade da Caatinga (p. 777-796). In: Leal I.R., Tabarelli M. \& Silva J.M.C. (Eds). Ecologia e Conservação da Caatinga. Recife: UFPE. 822 p.

Teodoro P.H.M. \& Amorim M.C.C.T. (2008) Mudanças climáticas: algumas reflexões. Revista Brasileira de Climatologia, 3: 25-35.

Veríssimo M.E.Z. (2003) Algumas considerações sobre o aquecimento global e suas repercussões. Terra Livre, 1(20): 137-143. 